\title{
Controls on hydrologic similarity: role of nearby gauged catchments for prediction at an ungauged catchment
}

\author{
S. Patil ${ }^{1,{ }^{*}}$ and M. Stieglitz ${ }^{1,2}$ \\ ${ }^{1}$ School of Civil and Environmental Engineering, Georgia Institute of Technology, Atlanta, GA, USA \\ ${ }^{2}$ School of Earth and Atmospheric Sciences, Georgia Institute of Technology, Atlanta, GA, USA \\ * currently at: National Health and Environmental Effects Research Laboratory, US Environmental Protection Agency, \\ Corvallis, OR, USA
}

Correspondence to: S. Patil (sopan.patil@gmail.com)

Received: 28 September 2011 - Published in Hydrol. Earth Syst. Sci. Discuss.: 19 October 2011

Revised: 14 February 2012 - Accepted: 19 February 2012 - Published: 23 February 2012

\begin{abstract}
Prediction of streamflow at ungauged catchments requires transfer of hydrologic information (e.g., model parameters, hydrologic indices, streamflow values) from gauged (donor) to ungauged (receiver) catchments. A common metric used for the selection of ideal donor catchments is the spatial proximity between donor and receiver catchments. However, it is not clear whether information transfer among nearby catchments is suitable across a wide range of climatic and geographic regions. We examine this issue using the data from 756 catchments within the continental United States. Each catchment is considered ungauged in turn and daily streamflow is simulated through distancebased interpolation of streamflows from neighboring catchments. Results show that distinct geographic regions exist in US where transfer of streamflow values from nearby catchments is useful for retrospective prediction of daily streamflow at ungauged catchments. Specifically, the high predictability catchments (Nash-Sutcliffe efficiency NS >0.7) are confined to the Appalachian Mountains in eastern US, the Rocky Mountains, and the Cascade Mountains in the Pacific Northwest. Low predictability catchments $(\mathrm{NS}<0.3)$ are located mostly in the drier regions west of Mississippi river, which demonstrates the limited utility of gauged catchments in those regions for predicting at ungauged basins. The results suggest that high streamflow similarity among nearby catchments (and therefore, good predictability at ungauged catchments) is more likely in humid runoff-dominated regions than in dry evapotranspiration-dominated regions. We further find that higher density and/or closer distance of gauged catchments near an ungauged catchment does not necessarily guarantee good predictability at an ungauged catchment.
\end{abstract}

\section{Introduction}

Long-term measurements of river streamflow are essential for a number of applications in water resources, such as, planning of water supply and irrigation projects (Dunne and Leopold, 1978; Jain and Singh, 2003), delineation of river floodplains (Merwade et al., 2008; Tate et al., 2002), dayto-day management of dams and canals (Hirsch and Costa, 2004), to name a few. Streamflow measurements are also important for characterizing the hydrologic behavior of river basins within modeling frameworks, so that future assessments of hydrologic behavior in response to climate and/or land-use change can be obtained. However, in many parts of the world, developed as well as developing, rivers are not gauged for continuous monitoring. Developing strategies for prediction at ungauged basins (PUB; Sivapalan et al., 2003) is required not only for the above practical applications, but also for advancing our process understanding of the controls on regional variability in landscape hydrologic response (Patil and Stieglitz, 2011; Wagener et al., 2004).

Prediction of streamflow at ungauged catchments involves the following steps: (1) identify the gauged (donor) catchments that are most likely to be hydrologically similar, i.e., have similar streamflow response, to the ungauged (receiver) catchments, and (2) transfer the relevant hydrologic information (model parameters or streamflow values) from the gauged to ungauged catchments. Identification of hydrologic similarity in this case is especially challenging, since the hydrologic behavior of ungauged catchments is unknown. Studies focusing on the transfer of parameters of rainfallrunoff models have typically used either physical proximity measures (e.g., topography, soil type, land cover) or 
spatial proximity measures (distance) as a surrogate for hydrologic similarity between the gauged and ungauged catchments (Götzinger and Bárdossy, 2007; Merz and Blöschl, 2004; Oudin et al., 2010; Parajka et al., 2005; Seibert, 1999). While either type of surrogates have their advantages and disadvantages, a key conceptual limitation of the spatial proximity measures is that they preclude identification of hydrologic similarity among catchments that might be located far from each other. Interestingly, studies that have compared different similarity surrogates show that, in spite of its conceptual limitations, ascribing hydrologic similarity based on spatial proximity measures is one of the most reliable methods for choosing donor gauged catchments from which rainfall-runoff model parameters can be transferred to ungauged catchments (Merz and Blöschl, 2004; Oudin et al., 2008; Zhang and Chiew, 2009).

Alternatively, methods that are used to predict at ungauged catchments without rainfall-runoff models perform direct transfer of streamflow time series from nearby gauged catchments (Archfield and Vogel, 2010; Skøien and Blöschl, 2007). These methods are inherently restricted to using spatial proximity based similarity measures since streamflow transfer from far away catchments will cause large errors (due to climate heterogeneity). Nonetheless, the streamflow predictability patterns obtained from these methods have the potential to inform us whether nearby catchments within a given region are hydrologically similar or not. The drainagearea ratio method (Hirsch, 1979; Wiche et al., 1989) is perhaps the oldest method used for direct transfer of streamflow values to ungauged catchments. In this method, a gauged catchment that is located nearest to the ungauged catchment of interest is identified as hydrologically similar, and areanormalized streamflow values are transferred from gauged to ungauged catchment. More recently, Smakhtin et al. (1997) developed regionalized flow duration curves for catchments in South Africa and estimated streamflow at ungauged catchments through the transfer of daily streamflow data from nearby gauged catchments using an interpolation technique described in Hughes and Smakhtin (1996). Archfield and Vogel (2010) developed the map-correlation method to identify the donor gauged catchment that is likely to have high correlation to the ungauged catchment for direct transfer of daily streamflow time series. Skøien and Blöschl (2007) used the concept of topological kriging, or top-kriging (Skøien et al., 2006), on 376 catchments in Austria to predict hourly and daily streamflow in ungauged catchments.

Results from either of the above approaches (rainfallrunoff model based or model independent) highlight the importance of spatial proximity as a criterion for the selection of donor gauged catchments. While spatial proximity is a widely used measure for predicting at ungauged catchments, it is not clear whether transferring information among nearby catchments is a suitable approach across a wide range of climatic and geographic regions. Specifically, we do not know if hydrologic similarity among nearby catchments can be expected everywhere, or if there are certain types of regions (e.g., with humid climate, or with mountainous terrain, etc.) where hydrologic similarity is preferentially manifested.

The objective of this study is to: (1) determine if distinct geographic regions exist where nearby catchments tend to have similar streamflow patterns, so that information can be easily transferred between gauged and ungauged catchments, and (2) identify the physiographic and hydro-climatic conditions that favor streamflow similarity among nearby catchments within a region. We use the data from 756 gauged catchments across the continental United States that span a wide range of climatic, geologic and topographic conditions. Similarity among nearby catchments is quantified through direct transfer of daily area-normalized streamflow values from neighboring gauged catchments using inverse distance weighted (IDW) interpolation. While this method is a variant of the drainage-area ratio method (Hirsch, 1979), it improves upon the traditional method due to its ability to transfer information from multiple donor gauged catchments to an ungauged catchment. We specifically avoided rainfall-runoff models in this study since no single model structure can perform satisfactorily across the wide range of catchments considered here. As such, our analysis of hydrologic similarity among nearby catchments focuses solely on the observed streamflow patterns and is independent of the deficiencies associated with any particular rainfall-runoff model structure. High prediction efficiency using the interpolation method suggests that nearby catchments in that region have similar streamflow patterns to the catchment of interest. The prediction efficiency of transferred streamflow values is further compared against physiographic and hydro-climatic properties of the catchments to identify the conditions that favor high streamflow similarity within a region.

\section{Data}

We use the streamflow records of catchments from US Geological Survey's Hydro-Climate Data Network (HCDN) (Slack et al., 1993). The HCDN database consists of data of 1659 catchments located within the United States that are not severely affected by human activity. The streamflow records in HCDN span from 1874 to 1988. A majority of the catchments have consistent and continuous records from water year 1970 onwards. As such, we consider only those catchments that have a continuous daily streamflow record from water year 1970 to 1988 (i.e., 1 October 1969 to 30 September 1988), which reduces the number of acceptable catchments to 756 (see Fig. 1). The drainage area of the catchments ranges from $23 \mathrm{~km}^{2}$ to $5000 \mathrm{~km}^{2}$, and the median drainage area is $715 \mathrm{~km}^{2}$.

Monthly time-series of precipitation and potential evapotranspiration in each of the 756 catchments are obtained from the climate dataset developed by Vogel and Sankarasubramanian (2005). Estimates of monthly precipitation in 


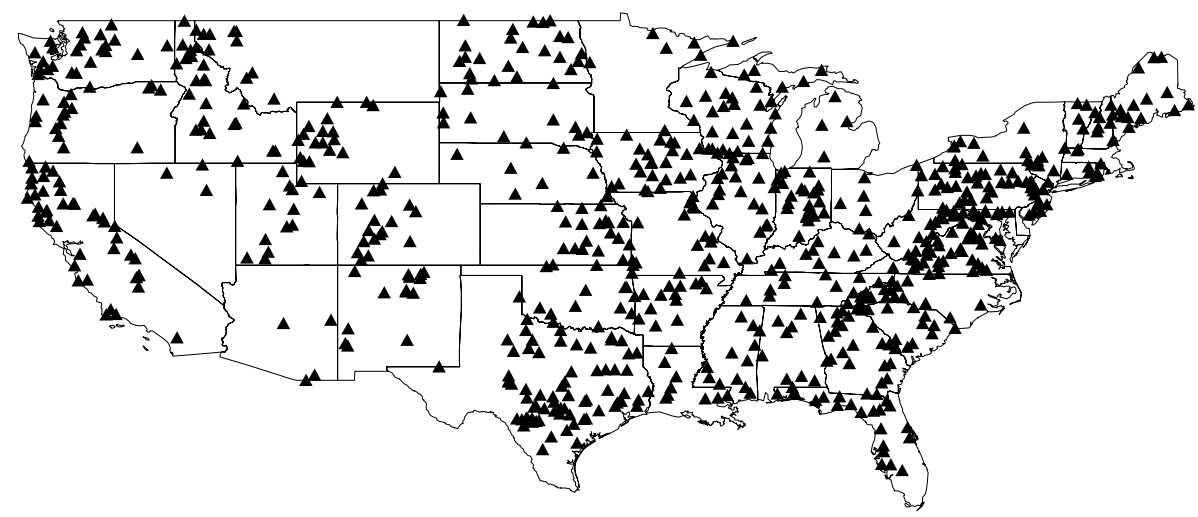

Fig. 1. Location of all the 756 catchments (black triangles) within the continental US.

this dataset are obtained from the PRISM (Daly et al., 1994) climate analysis system as described in Vogel et al. (1999), whereas the monthly potential evapotranspiration estimates are obtained using the formula suggested by Hargreaves and Samani (1982). From the streamflow and precipitation data, we derive five hydrologic indices (or signatures) for each of the 756 catchments. These hydrologic signatures are: baseflow index, runoff ratio, baseflow runoff ratio (baseflow/rainfall), slope of flow duration curve, and interannual streamflow elasticity. We also use the data of three physiographic attributes from Vogel and Sankarasubramanian (2005) dataset, viz., channel slope, soil permeability, and soil water holding capacity. Details of the methods used for deriving these hydrologic signatures are provided in Appendix A.

As illustrated in Fig. 1, the number of stream gauges is higher in the eastern half of the country than in the western half. Since the streamflow predictions obtained in this study are based on the proximity of gauged and ungauged catchments, it is not entirely clear whether this variable gauge density induces bias in our analysis. Therefore, in Sect. 4.3, we evaluate whether gauge density has any appreciable effect on streamflow predictions at ungauged catchments.

\section{Methods}

In this section, we first outline the distance based interpolation method used for simulating daily streamflow. We then describe the goodness-of-fit measure used for assessing the prediction efficiency, followed by a brief explanation of the metric used for assessing the relationships between prediction efficiency and catchment properties.

The inverse distance weighted (IDW) interpolation is one of the simplest methods to determine whether streamflow values among spatially proximate catchments are similar. Nonetheless, as will be shown in results, this method is highly effective in characterizing the streamflow similarity patterns over the scale of continental US. Comparison of different interpolation methods is beyond the scope of this study (but see the discussion in Sect. 5). The IDW streamflow interpolation method is a variant of the drainage-area ratio method (Hirsch, 1979; Wiche et al., 1989). In the traditional drainage-area ratio method, area normalized streamflow values are directly transferred to an ungauged catchment from a single donor catchment that is in the closest geographic proximity. The IDW interpolation method used here modifies the drainage-area ratio method, specifically by allowing for direct streamflow transfer from multiple donor gauged catchments. As we will show later in the results (Sect. 4), expanding the drainage-area ratio method to consider multiple donor catchments significantly improves the prediction performance at ungauged catchments. The mathematical expression of the IDW interpolation scheme is as follows:

$q(x)=\sum_{k=1}^{N} \frac{w_{k}(x)}{\sum_{k=1}^{N} w_{k}(x)} \cdot q\left(x_{k}\right)$

and,

$w_{k}(x)=\frac{1}{d\left(x, x_{k}\right)^{p}}$

where, $q(x)$ is the area-normalized streamflow value (unit: mm day ${ }^{-1}$ ) at the ungauged catchment that is located at point $x$ in the region, $q\left(x_{k}\right)$ is the area-normalized streamflow value at neighboring donor catchment $k$ located at point $x_{k}$ in the region, and $N$ is the total number of neighboring donor catchments considered for the interpolation. Distance between the gauged and ungauged catchment $d$ is calculated individually for each of the $N$ neighboring catchments. $d$ is the distance between stream gauges of the catchments. The interpolation weights $w$ are calculated for all the donor catchments using Eq. (2). The exponent $p$ in Eq. (2) is a positive real number, called as power parameter. The above streamflow transfer method does not account for precipitation lags or differences in the timing of floods that 

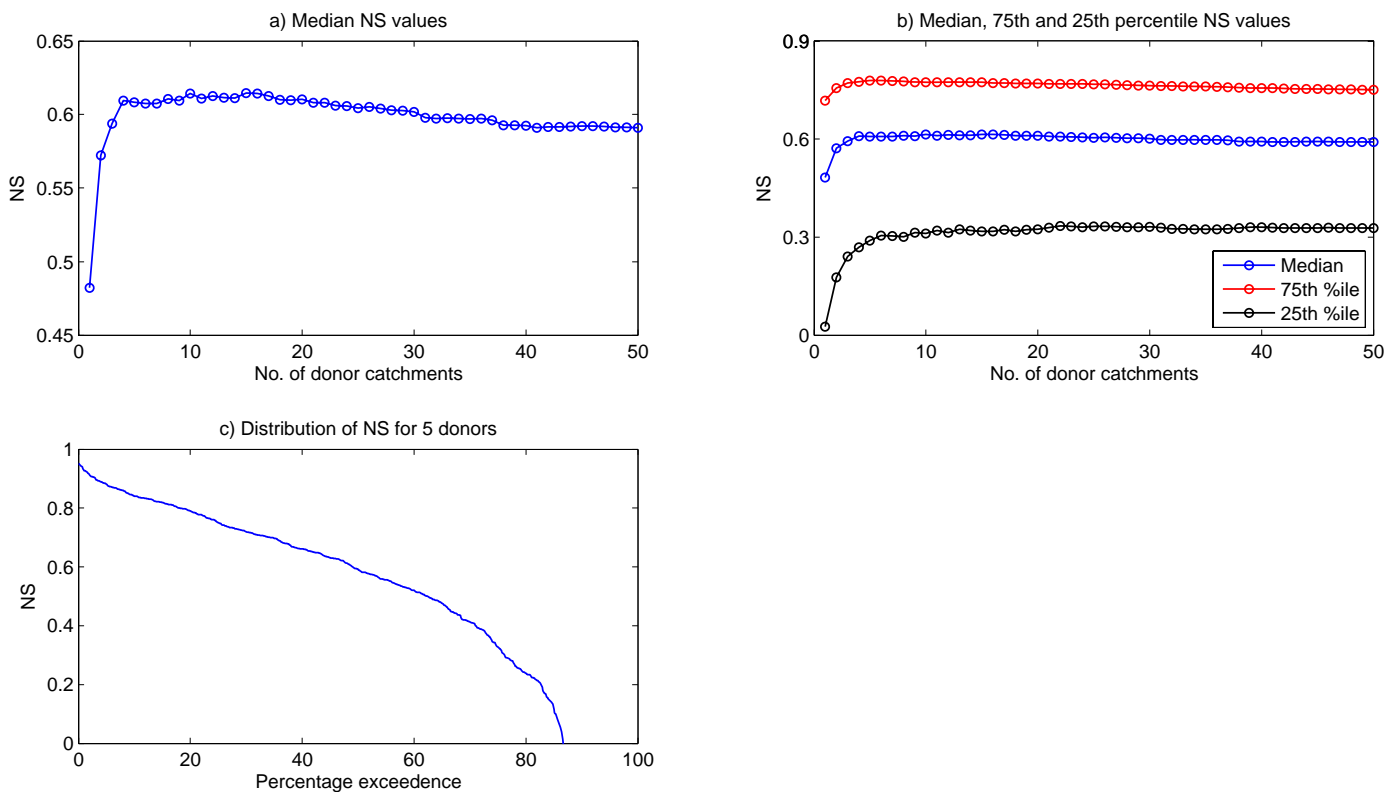

Fig. 2. (a) Relationship between number of donor catchments and median NS values, (b) relationship between number of donor catchments and median, 75th percentile, and 25th percentile NS values, and (c) distribution of NS values of simulated streamflows for the configuration of five donor catchments.

may occasionally occur among nearby catchments. However, studies that have explicitly considered for precipitation and flood timing lags show that streamflow transfer is usually sensitive to lags at the hourly timescale, but not at the daily timescale (Andréassian et al., 2012; Skøien and Blöschl, 2007). Since our study focuses on streamflow transfer at the daily timescale, this simplification is not likely to affect our prediction results.

Each of the 756 catchments is considered ungauged in turn (jack-knife procedure), and daily streamflows are simulated using Eqs. (1) and (2). We use power parameter $p=2$ (i.e., the inverse square distance weighted method) and vary the number of neighboring donor catchments $N$ from 1 to 50 . As a special case, when $N=1$, the IDW interpolation method is equivalent to the traditional drainage-area ratio method.

Goodness of fit for predicted hydrograph is measured using the Nash-Sutcliffe efficiency criterion (NS), which is defined as follows (Nash and Sutcliffe, 1970):

$\mathrm{NS}=1-\frac{\sum_{i=1}^{n}\left(Q_{\mathrm{obs}, i}-Q_{\mathrm{pred}, i}\right)^{2}}{\sum_{i=1}^{n}\left(Q_{\mathrm{obs}, i}-\bar{Q}_{\mathrm{obs}}\right)^{2}}$

where, $Q_{\text {pred, } i}$ and $Q_{\mathrm{obs}, i}$ are the predicted and the observed area-normalized streamflow values (unit: $\mathrm{mm} \mathrm{day}^{-1}$ ) on the $i$-th day respectively, $\bar{Q}_{\mathrm{obs}}$ is the mean of all the observed streamflow values (unit: $\mathrm{mm} \mathrm{day}^{-1}$ ) and $n$ is the total number of days in the record. The NS efficiency criterion is an extensively used metric in the hydrology literature to determine the simulation efficiency of daily hydrographs. We further analyze the relationship of prediction efficiency (NS values) with numerous physical and hydrological properties of a catchment. These relationships are analyzed to identify the factors that favor streamflow similarity among nearby catchments. To this end, we use the Spearman's rank correlation (Spearman, 1904), which quantifies the increasing/decreasing trend in a relationship. The formula for Spearman's correlation $(\rho)$ is as follows:

$\rho=1-\frac{6 \cdot \sum d^{2}}{M \cdot\left(M^{2}-1\right)}$

where, $d$ is the difference between the ranks of each observation on the two variables under consideration, and $M$ is the total number of observation points ( $M=756$ in our case). Spearman's $\rho$ varies from -1 to +1 , with -1 being a perfect monotonically decreasing relationship and +1 being perfect monotonically increasing.

\section{Results}

\subsection{Choosing the optimal number of donor gauged catchments}

To find the optimal number of donor catchments required for a good streamflow estimate we vary the number of nearest donor catchments from 1 to 50 and calculate the associated NS. This approach for choosing the optimal number of donors has been used previously (Oudin et al., 2008; Zhang and Chiew, 2009). Figure 2a shows the relationship between 

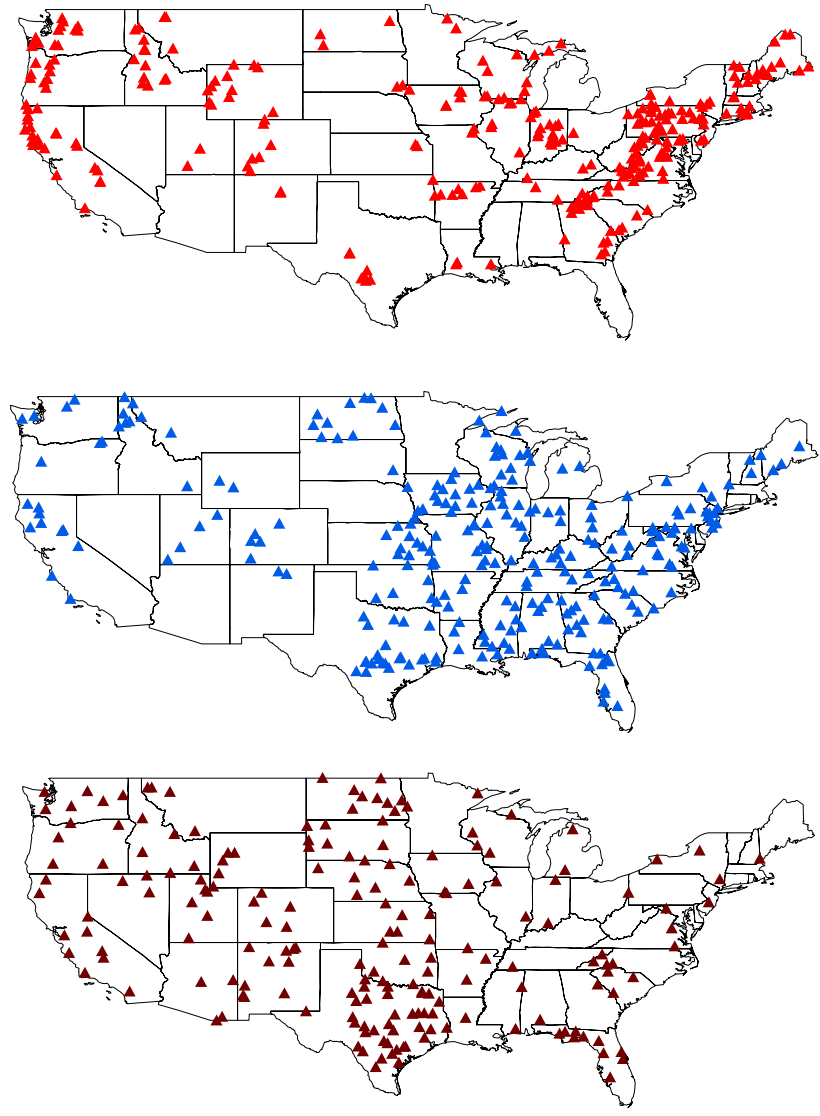

Fig. 3. (a) Group 1 catchments with $\mathrm{NS}>0.7$ (red triangle), (b) Group 2 catchments with $0.3<\mathrm{NS}<0.7$ (blue triangle), and (c) Group 3 catchments with NS $<0.3$ (brown triangle).

the number of donor gauged catchments used for simulating daily streamflow and the median NS from each simulation run for all the 756 catchments. The median NS increases sharply from 0.49 to 0.61 as the number of donor catchments increase from 1 to 4 , followed by small increases in median NS for subsequent increases in the number of donor catchments. The median NS reaches its highest value of 0.615 at 15 donor catchments. Beyond 15 donor catchments there is decline in simulation efficiency that can be attributed to the relative reduction in influence of the nearby catchments. For subsequent analysis, we limit the number of donors to five nearest gauged catchments and perform the distance based interpolation to simulate daily streamflows. For simulations with five donor catchments, the maximum NS is 0.97 , the median value is 0.61 , and the 25 th percentile value is 0.29 . Figure $2 \mathrm{~b}$ shows the 25 th and 75 th percentile NS values along with median NS against the number of donor catchments. Similar to the median, other percentile values also show that increasing the number of donors far beyond 4 or 5 does not cause an increase in prediction performance. Figure $2 \mathrm{c}$ shows the distribution of NS values of simulated streamflows using five donor catchments.
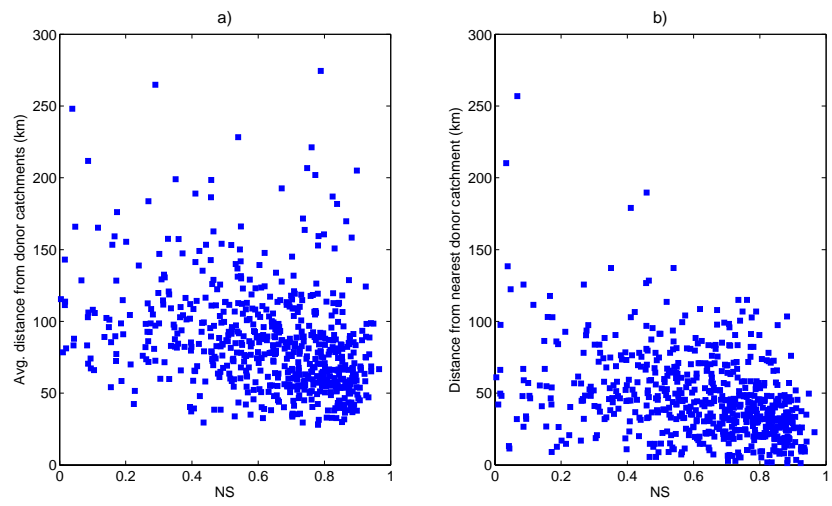

Fig. 4. Relationship of Nash Sutcliffe efficiency (NS) with (a) average distance from donor catchments, and (b) distance from nearest donor catchment.

\subsection{Geographic patterns of daily streamflow prediction}

Distinct geographic patterns are observed in the NS values of catchment streamflows using the IDW interpolation method (Fig. 3). For better identification of these geographic patterns, we partition the catchments into three groups: Group 1 for NS greater than 0.7, Group 2 for NS between 0.3 and 0.7 , and Group 3 for NS less than 0.3. Figure 3a shows the location of all the Group 1 catchments, 288 in total ( 40\%), which have the highest predictability of daily streamflow. The majority of Group 1 catchments are located in three geographic regions: (1) the Appalachian mountain ranges in the eastern US, (2) the Rocky Mountains, and (3) the Pacific Northwest region to the west of Cascade Mountain range. The remaining Group 1 catchments are located across the eastern half of continental US, especially in the states of Indiana and Illinois (Fig. 3a). The Group 2 catchments - a total of 277 catchments ( $35 \%)$; Fig. $3 \mathrm{~b}-$ are located across the eastern part of the United States. The poorest performers, Group 3 catchments are predominantly located in the western half of continental US, especially to the west of Mississippi river (Fig. 3c). There are 191 catchments $(\sim 25 \%)$ that belong in Group 3 and these are considered as practically unpredictable using our spatial proximity based prediction method.

\subsection{Impact of catchment proximity and gauge density on prediction at ungauged catchments}

Figure 4a shows the relationship of prediction efficiency (NS) with the average distance of donor catchments from the ungauged catchment, while Fig. $4 \mathrm{~b}$ shows its relationship with the distance of nearest donor catchment. As expected, the observed trend is that high NS catchments have donor catchments in closer proximity, i.e., smaller distances. The Spearman rank correlation $(\rho)$ for the relationships of NS with the average and minimum distance is -0.44 and -0.41 respectively ( $\mathrm{p}$-value $<0.01$ in both cases). However, at 


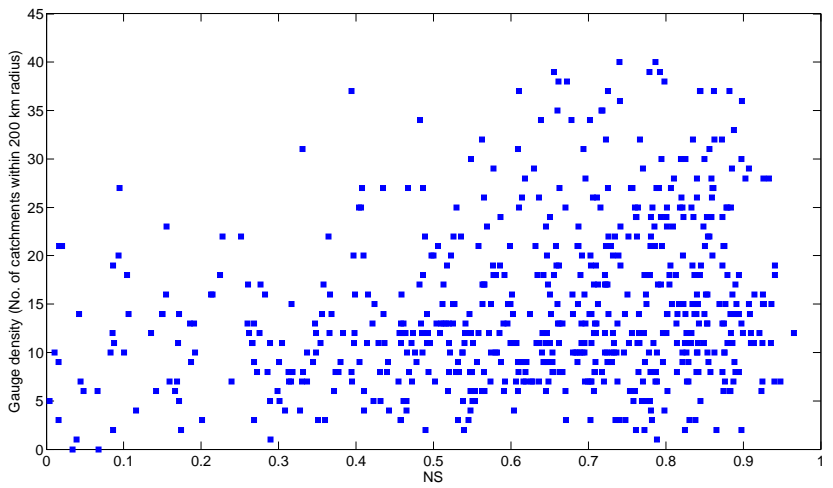

Fig. 5. Relationship of Nash Sutcliffe efficiency (NS) with gauge density around an ungauged catchment.

any given NS value, there is a surprisingly wide scatter of distances between donor and receiver catchments (Fig. 4a and $b$ ). This suggests that the donor-receiver catchment proximity alone cannot fully explain the prediction performance at a given location. Among catchments with NS $>0$, the $R^{2}$ value of relationship between NS and average donor distance is 0.12 , i.e., the average distance from donor catchments explains only $12 \%$ of the spatial variability in NS.

Gauge density is another important factor that influences the transfer of information to ungauged catchments. If more gauged catchments are present in the vicinity of an ungauged catchment, we can intuitively expect that catchment to have better predictability. Therefore, we test quantitatively whether disparity in gauge density across different regions of the US influences predictability at an ungauged catchment. Gauge density around a catchment is defined as the number of gauged catchments within the $200 \mathrm{~km}$ radius of its location. We tested the gauge density metric by varying the search radius from $100 \mathrm{~km}$ to $500 \mathrm{~km}$ and found that the relationship between NS and gauge density is not affected by the choice of the search radius (result not shown). Figure 5 shows the relationship between NS and gauge density near the ungauged catchment. Contrary to our a priori expectation, high gauge density around an ungauged catchment does not guarantee good predictability. Moreover, there are numerous catchments that have low gauge density in their vicinity and still have high NS values. No significant trend is observed in the relationship between NS and gauge density. Among catchments with NS $>0$, the $R^{2}$ value of relationship between NS and gauge density is 0.06 , i.e., the density of gauged catchments surrounding within a region explains only $6 \%$ of the spatial variability in NS.

\subsection{Impact of climate on prediction at ungauged catchments}

We analyze the high and low predictability catchments using the Budyko curve (Budyko, 1974). A Budyko curve

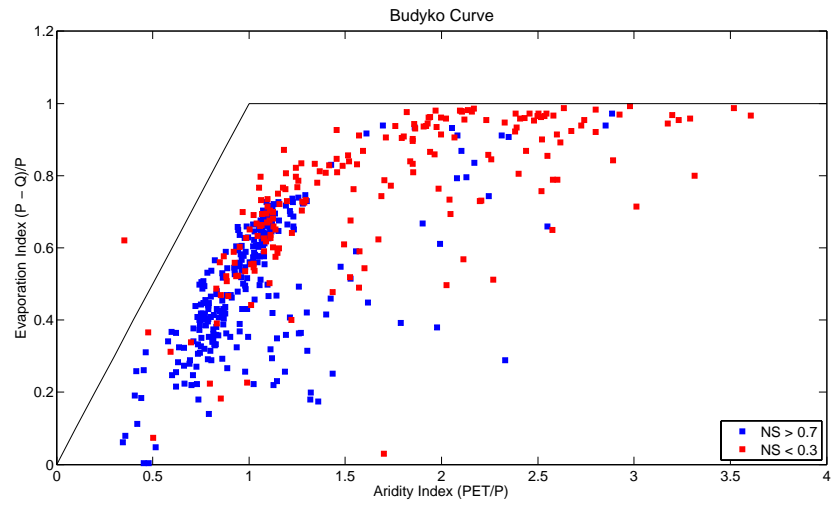

Fig. 6. Budyko diagram showing the high predictability $(\mathrm{NS}>0.7)$ and low predictability (NS $<0.3$ ) catchments.

characterizes the relationship between aridity index (PET/P) and evaporation index $(\mathrm{ET} / P)$ of the catchments. Figure 6 shows the Group 1 catchments (NS $>0.7$, blue squares) and Group 3 catchments (NS $<0.3$, red squares) on the Budyko curve. Majority of the high predictability catchments (Group 1) have low values of evaporation and aridity indices and are located in the lower portion of the curve. This suggests that the water balance in these high predictability catchments is controlled by energy limitation, i.e., more water is present than can be evaporated. On the other hand, low predictability catchments (Group 3) have higher values of evaporation and aridity indices and are located in the higher portion of the curve. About $48 \%$ of the Group 3 catchments have aridity index $>1$, suggesting that their water balance is controlled by water limitation, i.e., less water is present than can be evaporated. Thus, the Budyko curve shows that the predictability is higher in regions where the ET of catchments is demand limited (i.e., humid) and low where the ET is supply limited (i.e., arid).

\subsection{Physical conditions favoring good prediction at ungauged catchments}

To identify the physical conditions that favor high streamflow similarity (and therefore good predictability), we explore the relationships between NS and catchment attributes. Eight catchment properties are considered: three physiographic properties (channel slope, soil permeability, and soil water holding capacity) that are obtained for each catchment from the Vogel and Sankarasubramanian (2005) dataset; and five hydrologic signatures (baseflow index, runoff ratio, baseflow runoff ratio, slope of flow duration curve, and inter-annual streamflow elasticity) that are derived from the streamflow and precipitation data (see Appendix A for details).

Figure 7 shows the relationship between prediction efficiency (NS) and each of the three physiographic properties. While none of these properties have a distinct relationship with NS, a majority of the catchments with higher channel 

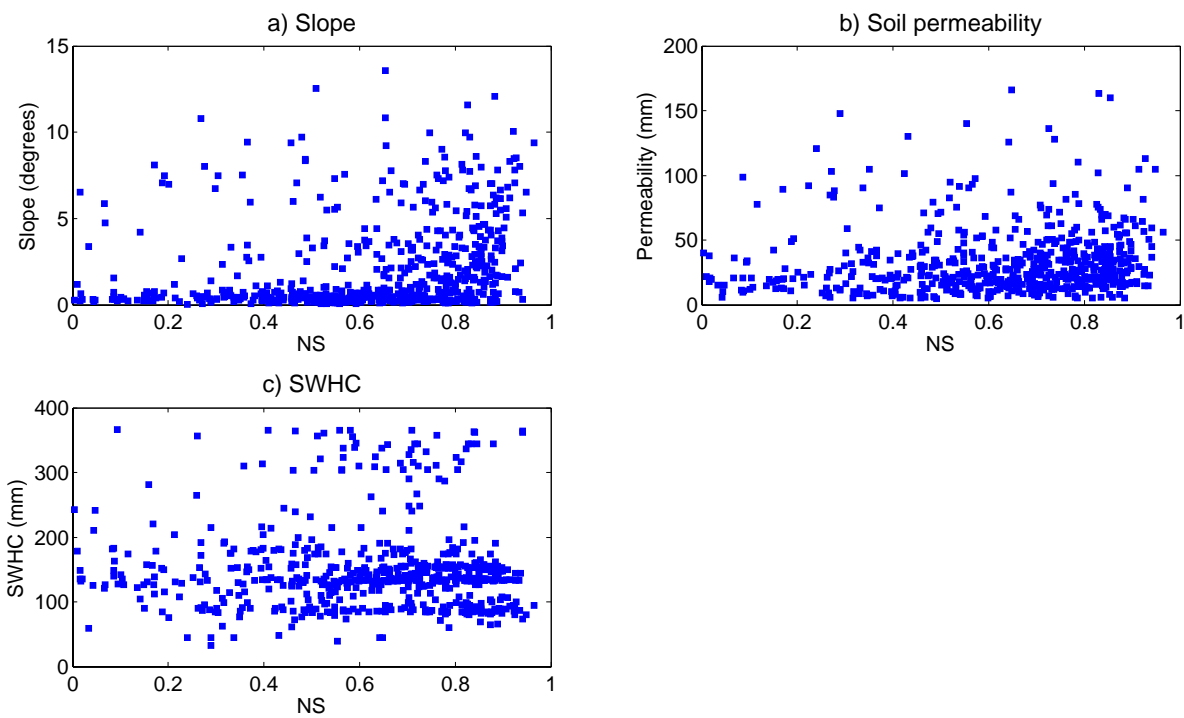

Fig. 7. Relationship between Nash Sutcliffe efficiency (NS) and (a) channel slope, (b) soil permeability, and (c) soil water holding capacity (SWHC).

slope $(>1 \%)$ have high NS value (Fig. 7a). This trend is consistent with the observation that a majority of high NS catchments are located along the three large mountain ranges of the US (Fig. 3a). However, high NS values are not exclusive to catchments with high channel slope. Of the three physiographic properties, only channel slope shows a statistically significant trend in its relationship with NS (Spearman $\rho=0.21$; see Table 1 ). No distinct trend is observed in soil permeability except that the preference of higher permeability catchments is towards high NS values (Fig. 7b). No trend whatsoever is observed in the relationship between NS and soil water holding capacity (Fig. 7c).

Figure 8 shows each of the five hydrologic signatures plotted against NS. High scatter is observed in all the five relationships, similar to the observations of physiographic attributes (Fig. 7). Nonetheless an increasing trend with respect to NS is observed in the relationships of runoff ratio (Spearman $\rho=0.51$ ), baseflow runoff ratio (Spearman $\rho=0.46$ ), and slope of FDC (Spearman $\rho=0.31$ ) (Fig. 8a, c, and $d$ respectively). Although many high NS catchments are clustered towards high values of baseflow index (Fig. 8b), it does not have a significant trend in its relationship with NS. No particular trend (increasing or decreasing) is observed in the relationship between NS and streamflow elasticity (Fig. 8e).

\section{Discussion}

Distinct geographic regions exist where identifying similarity and transferring streamflow based on the spatial proximity measure results in good prediction at an ungauged catchment. High streamflow predictability is obtained in
Table 1. Correlation of catchment properties with Nash-Sutcliffe (NS) efficiency of simulation. Bold values indicate statistically significant value $(p<0.01)$.

\begin{tabular}{llcc}
\hline Type & Property & $\begin{array}{c}\text { Spearman rank } \\
\text { correlation }(\rho)\end{array}$ & p-value \\
\hline Physiographic & Channel slope & $\mathbf{0 . 2 1}$ & 0.00 \\
& Soil permeability & 0.08 & 0.03 \\
& SWHC & 0.04 & 0.26 \\
\hline Hydrologic & Runoff ratio & $\mathbf{0 . 5 1}$ & 0.00 \\
& Baseflow index & 0.03 & 0.46 \\
& Baseflow runoff ratio & $\mathbf{0 . 4 6}$ & 0.00 \\
& Slope of FDC & $\mathbf{0 . 3 1}$ & 0.00 \\
& Streamflow elasticity & 0.01 & 0.83 \\
\hline
\end{tabular}

humid mountainous regions, whereas the low predictability catchments are predominantly located in the drier regions (Fig. 3). To our knowledge, the geographic patterns of streamflow similarity (and predictability at ungauged catchments) shown here have not been shown before within the continental US, specifically at a daily time-scale and by using an information transfer method. The Budyko curve (Fig. 6) illustrates the preference of high predictability catchments towards humid regions. Our previous work (Patil and Stieglitz, 2011) characterized streamflow similarity among nearby catchments across multiple flow conditions. Patil and Stieglitz (2011) suggested that the competing influences of precipitation input and evaporative demand determine the conditions at which regional streamflow similarity is manifested. Consistent with their suggestion, the results presented here show that streamflow similarity among nearby 

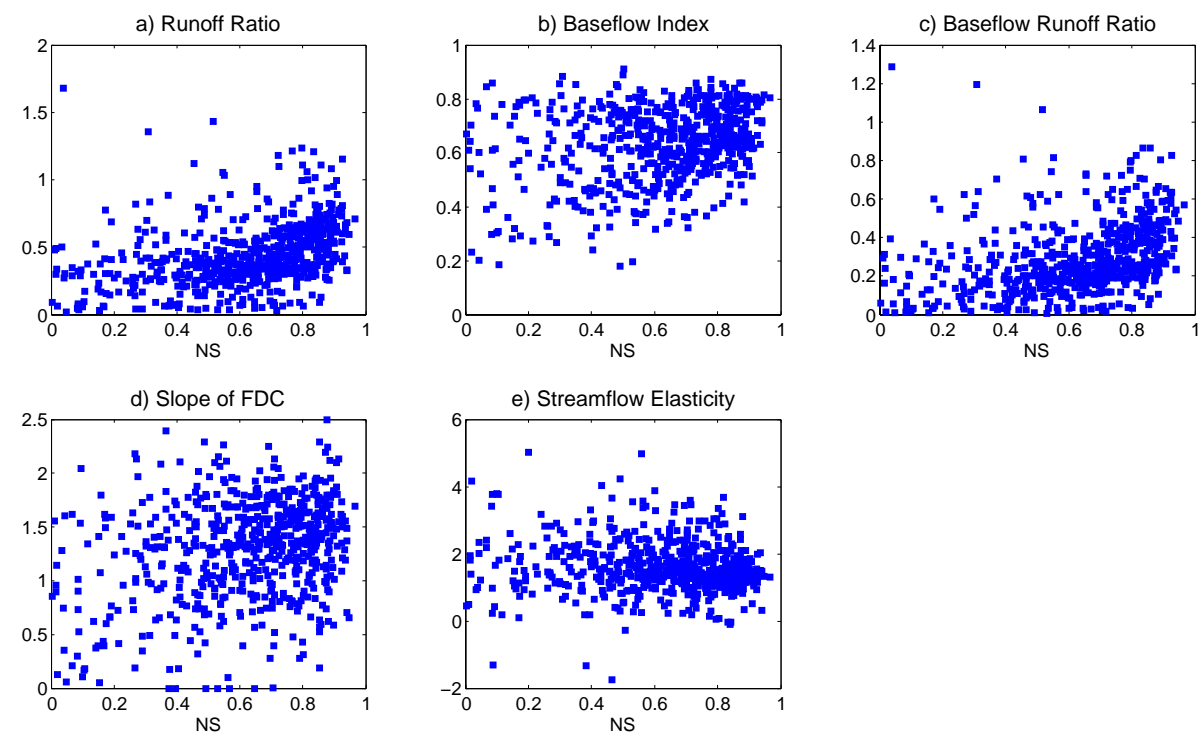

Fig. 8. Relationship between Nash Sutcliffe efficiency (NS) and (a) runoff ratio, (b) baseflow index, (c) baseflow runoff ratio, (d) slope of FDC, and (e) streamflow elasticity.

catchments is more likely to occur in regions where annual precipitation exceeds evaporative demand (i.e., low energy environments). The preference for humid environment is further evident from the tendency of high predictability catchments to be located in regions of high forest density. Figure 9 shows all the 756 catchments mapped with the forest cover within the US. The forest cover map is obtained from the USGS Global Land Cover Characteristics (GLCC) project (Loveland et al., 1991). With the exception of catchments in the mid-West, almost all the high predictability catchments (Group 1) are located in regions with high amount of forest cover.

While humid climate is certainly favorable for similarity among nearby catchments, climate alone does not appear to be sufficient for identifying regions of high streamflow similarity. The clustering of Group 1 catchments along the mountain ranges suggests that topography is also an important factor in determining streamflow similarity (and predictability). For instance, the catchments in southeastern states of Louisiana, Mississippi, Alabama and Florida have humid climate, but a flatter terrain (and most are Group 2 catchments). Due to the strong connection of predictability with geographic features, we had an a priori expectation that the catchments with high (or low) predictability will have distinct physiographic and hydrologic signatures associated with them. However, the relationship of NS with individual catchment properties is weak. This suggests that the strong differences in climate within the continental US might be, to some extent, obscuring the physiographic differences among catchments. It is not clear though whether the physical catchment properties can better explain the predictability patterns at smaller regional scales where the climate is more homogeneous. Of the eight catchment properties considered, statistically significant positive trends with respect to NS are observed in only four properties: channel slope, runoff ratio, baseflow runoff ratio, and the slope of FDC (see Table 1). These weak relationships are also indicative of the difficulties faced by hydrologists in achieving a universally acceptable hydrologic classification of catchments (McDonnell et al., 2007; Wagener et al., 2007).

The IDW streamflow interpolation method, although mathematically simpler, is conceptually similar to other streamflow transfer methods (Andréassian et al., 2012; Archfield and Vogel, 2010; Skøien and Blöschl, 2007). These methods typically involve choosing $N$ nearest neighbors and assigning an appropriate weighting scheme to transfer areanormalized streamflow to the ungauged catchment. Due to the large scale of continental US considered in this study, and also due to the low streamgage density (compared to European studies such as Young, 2006; Skøien and Blöschl, 2007; Oudin et al., 2008; Andréassian et al., 2012), we do not think that our simple method is at a disadvantage for identifying the large scale predictability patterns (as seen in Fig. 3). A more sophisticated streamflow transfer method is likely to provide better results at smaller regional scales where higher streamgage density is available. Nonetheless, in regions with low streamgage density, even a mathematically sophisticated method is unlikely to provide good predictions at ungauged catchments. Unfortunately, since all the above mentioned methods use spatial proximity based similarity measures, they cannot identify a gauged catchment that is potentially similar to the ungauged catchment but is located far from it. Physical proximity measures (e.g., topography, soil type, land cover) are conceptually more appealing 


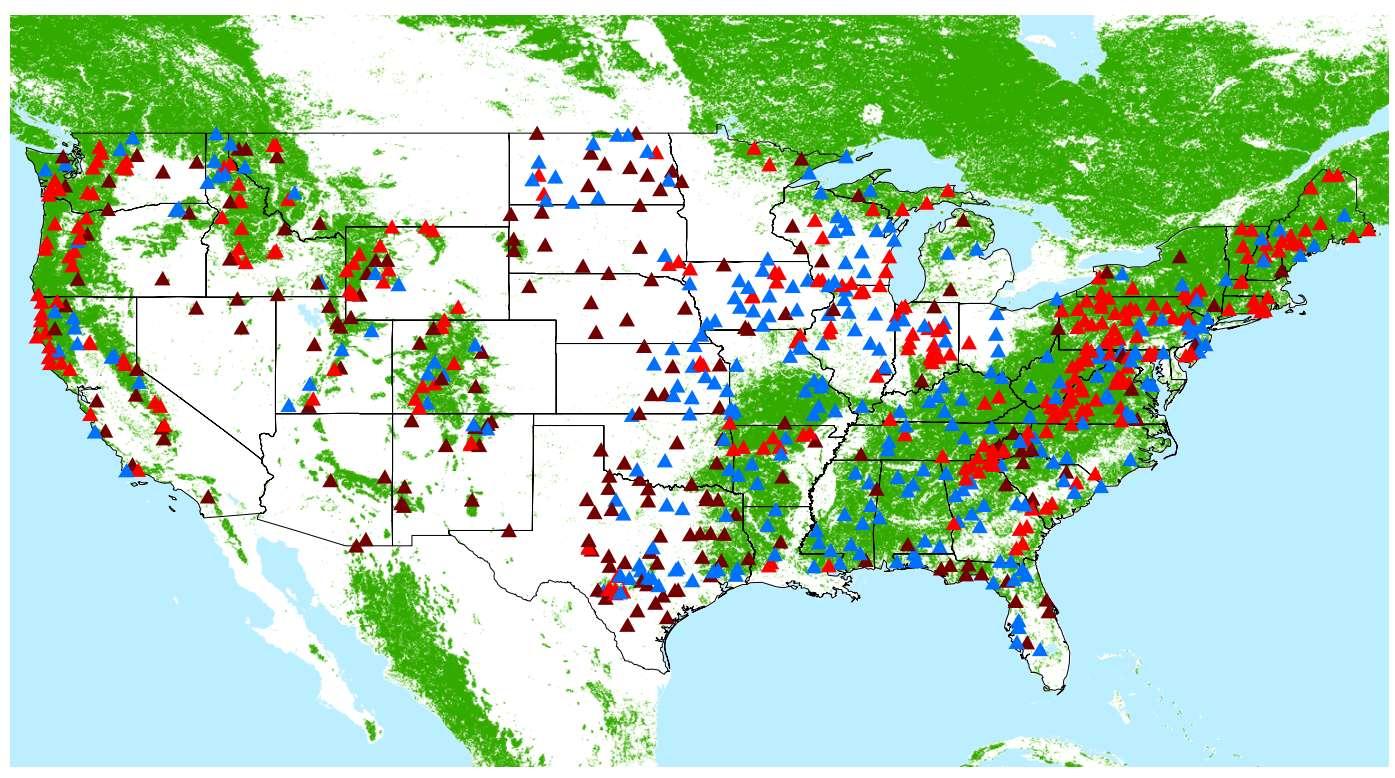

Fig. 9. All the 756 catchments mapped along with the forest cover within the United States: Group 1 (NS $>0.7$; red), Group 2 $(0.7>$ NS > 0.3; blue), Group 3 (0.3 > NS; brown).

since they can identify similarity among catchments that are far from each other. However, recent studies have shown that physical proximity measures do not necessarily provide better prediction at ungauged catchments than spatial proximity measures (Oudin et al., 2008; Zhang and Chiew, 2009).

Even though the predictions at ungauged catchments in this study are obtained through distance-based interpolation, results show that the distance between donor and receiver catchments cannot fully explain the prediction patterns. It could have been argued that the high NS catchments are preferentially located in humid regions because of the higher gauge density in those regions. However, no clear relationship is found between NS and gauge density either (Fig. 5). This suggests that factors other than spatial proximity among catchments and gauge density play an important role in regional similarity of streamflows. The higher predictability in humid environments is likely to be due to similarity in climatic inputs over larger spatial scales. However, low predictability at an ungauged catchment can be due to either one of the three primary causes: (1) the ungauged catchment is too far from the donor catchments, or (2) the spatial variability in climatic inputs is high in the region surrounding the ungauged catchment, or (3) the hydrologic behavior of the ungauged catchment is idiosyncratic (and therefore, nonrepresentative of the region surrounding it) either due to contributions from deep groundwater sources, loss of water to regional aquifers, or other complex geologic factors.

\section{Summary and conclusion}

This study examined whether identification of hydrologic similarity based on spatial proximity measures is suitable for prediction at ungauged catchments across multiple environments. Distinct geographic patterns of daily streamflow predictability at ungauged catchments were observed within the continental US. Specifically, high predictability catchments are located along the Appalachian Mountains in eastern US, the Rocky Mountains, and the Cascade Mountains in the Pacific Northwest, whereas the low predictability catchments are located in the drier regions west of Mississippi river. Identification of these patterns provides essential information regarding the usefulness of gauged catchments within a region for predicting streamflow at a nearby ungauged catchment. While the direct transfer of streamflows is useful for retrospective prediction, future forecasts of streamflows will still require implementation of rainfall-runoff models. Although this study did not test the transferability of rainfallrunoff model parameters to ungauged catchments, we did identify regions where nearby catchments tend to have similar streamflow patterns. Our speculation is that high streamflow similarity within a region certainly increases the likelihood of model parameters being similar at a regional scale. Therefore, we think that a map showing regions of high and low streamflow similarity (like Fig. 3) could be a good starting point when considering model parameter transfer to ungauged catchments. However, the model regionalization studies will need to additionally consider whether their chosen rainfall-runoff model structure is suitable for characterizing the hydrologic response within their region of interest. 
Comparison of catchments using the Budyko curve suggests that climate has a dominant control over the regional extent of similarity in hydrologic response. Nonetheless, among the humid regions, high predictability catchments are still preferentially clustered among the mountainous environments. This suggests that the topography of the region also has the ability to influence similarity in catchment streamflows. However, analysis of individual catchment attributes provides, at best, a weak picture of the physiographic and hydro-climatic conditions that favor high streamflow similarity (and predictability at ungauged catchments). More importantly, our results show that the spatial proximity between gauged and ungauged catchments alone cannot fully explain the prediction performance at a given location. This suggests that a combined influence of spatial proximity, regional climate variability and geologic settings contributes towards meaningful information transfer between the gauged and ungauged catchments.

\section{Appendix A}

\section{Deriving the hydrologic signatures of a catchment}

Five hydrologic indices (or signatures) are derived individually for each of the 756 catchments. These hydrologic signatures are: baseflow index, runoff ratio, baseflow runoff ratio, slope of flow duration curve, and inter-annual streamflow elasticity. Sawicz et al. (2011) used four of the above signatures (baseflow index, runoff ratio, slope of flow duration curve, and inter-annual streamflow elasticity) in their catchment classification study and showed that each individual hydrologic signature explains a different aspect of the hydrologic response of a catchment.

The baseflow index (BFI) is defined as the ratio of baseflow to total streamflow of a catchment. We use the one parameter single-pass digital filter method (Arnold and Allen, 1999; Eckhardt, 2008) to calculate the BFI. The baseflow filter is applied on daily streamflow time-series through the following equation:

$$
B_{k}=\alpha \cdot B_{k-1}+\frac{1-\alpha}{2} \cdot\left(Q_{k}+Q_{k-1}\right)
$$

where, $B$ is the baseflow and $Q$ is the total streamflow. The values of filter parameter $\alpha=0.925$. Equation (4) is applicable provided that $B \leq Q_{k}$ (or else $B_{k}=Q_{k}$ ). After applying the above filter, the baseflow index is calculated as:

$$
\mathrm{BFI}=\sum_{k=1}^{N} \frac{B_{k}}{Q_{k}}
$$

A high value of BFI suggests that the influence of subsurface flow on the overall flow output from a catchment is higher. On the other hand, a low BFI value suggests that the catchment is fast responding.
The runoff ratio (RR) is defined as the ratio of average annual streamflow $(Q)$ to average annual precipitation $(P)$. We consider the annual average values of $Q$ and $P$ over the entire period of WY 1970-1988 to calculate the RR values. The runoff ratio is a metric for partitioning the incoming precipitation input into the fraction that exits the catchment as runoff and the fraction that exits the catchment as evapotranspiration (Sankarasubramanian et al., 2001; Yadav et al., 2007). Catchments with high RR value are considered to be streamflow dominated, while those with low RR values are evapotranspiration dominated.

The baseflow runoff ratio is the ratio of average annual baseflow and precipitation. It is a similar metric to runoff ratio, but gives a direct estimate of the proportion of incoming rainfall that reaches the catchment outlet through slower subsurface paths. The baseflow runoff ratio is calculated as the product of baseflow index and runoff ratio of a catchment.

The flow duration curve (FDC) of a catchment is a graphical illustration of the amount of time (expressed as a percentage) a specific streamflow value is equaled or exceeded in a catchment within a specified period of hydrologic record (Searcy, 1959; Smakhtin, 2001). The slope of flow duration curve $\left(S_{\mathrm{FDC}}\right)$ is defined as the slope of the middle section of the FDC (between 33rd and 66th percentile flows) when the curve can be considered as approximately linear (Sawicz et al., 2011; Yadav et al., 2007). $S_{\text {FDC }}$ is calculated using the following formula:

$S_{\mathrm{FDC}}=\frac{\ln \left(Q_{66}\right)-\ln \left(Q_{33}\right)}{0.66-0.33}$.

A high value of $S_{\text {FDC }}$ indicates that the catchment is subject to high flow variability, while a low $S_{\text {FDC }}$ values is typical of catchments with damped response behavior and stable flows.

The inter-annual streamflow elasticity $\left(E_{Q P}\right)$ is defined as the ratio of percentage change in annual streamflow and the percentage change in annual precipitation. $E_{Q P}$ is an indicator of the sensitivity of streamflow to relative changes in precipitation inputs (Sankarasubramanian et al., 2001; Sawicz et al., 2011). We calculate the $E_{Q P}$ using the following formula:

$E_{Q P}=\operatorname{median}\left(\frac{d Q}{d P} \cdot \frac{P}{Q}\right)$.

An $E_{Q P}$ value of 1 suggests that the relationship between precipitation change and streamflow change is linear. $E_{Q P}>1$ indicates that the catchment is elastic (or more sensitive) to precipitation change, while $E_{Q P}<1$ indicates that the catchment is inelastic.

Acknowledgements. This research was supported by the following NSF grants: 0436118 and 0922100 . The authors would like to thank Alex Abdelnour, Yiwei Cheng, Andrea Butturini (editor) and the three anonymous reviewers for providing insightful comments that have greatly improved this manuscript.

Edited by: A. Butturini 


\section{References}

Andréassian, V., Lerat, J., Le Moine, N., and Perrin, C.: Neighbors: Nature's own hydrological models, J. Hydrol., 414-415, 49-58, doi:10.1016/j.jhydrol.2011.10.007, 2012.

Archfield, S. A. and Vogel, R. M.: Map correlation method: Selection of a reference streamgage to estimate daily streamflow at ungaged catchments, Water Resour. Res., 46, W10513, doi:10.1029/2009wr008481, 2010.

Arnold, J. G. and Allen, P. M.: Automated Methods for Estimating Baseflow and Ground Water Recharge from Streamflow Records, J. American Water Resour. Assoc., 35, 411-424, doi:10.1111/j.1752-1688.1999.tb03599.x, 1999.

Budyko, M. I.: Climate and life, Academic Press, 1974.

Daly, C., Neilson, R. P., and Phillips, D. L.: A StatisticalTopographic Model for Mapping Climatological Precipitation over Mountainous Terrain, J. Appl. Meteorol., 33, 140-158,

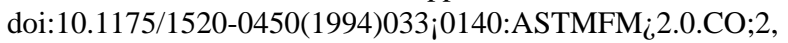
1994.

Dunne, T. and Leopold, L. B.: Water in environmental planning, WH Freeman \&Co., 1978.

Eckhardt, K.: A comparison of baseflow indices, which were calculated with seven different baseflow separation methods, J. Hydrol., 352, 168-173, doi:10.1016/j.jhydrol.2008.01.005, 2008.

Götzinger, J. and Bárdossy, A.:, Comparison of four regionalisation methods for a distributed hydrological model, J. Hydrol., 333, 374-384, doi:10.1016/j.jhydrol.2006.09.008, 2007.

Hargreaves, G. H. and Samani, Z. A.: Estimating potential evapotranspiration, J. Irrig. Drain. Div., 108, 225-230, 1982.

Hirsch, R. M.: An evaluation of some record reconstruction techniques, Water Resour. Res., 15, 1781-1790, doi:10.1029/WR015i006p01781, 1979.

Hirsch, R. M. and Costa, J. E.: U.S. stream flow measurement and data dissemination improve, Eos Trans. AGU, 85, doi:10.1029/2004eo200002, 2004.

Hughes, D. A. and Smakhtin, V.: Daily flow time series patching or extension: a spatial interpolation approach based on flow duration curves, Hydrolog. Sci. J., 41, 851-871, doi:10.1080/02626669609491555, 1996.

Jain, S. K. and Singh, V. P.: Water resources systems planning and management, Elsevier Science, 2003.

Loveland, T. R., Merchant, J. W., Ohlen, D. O., and Brow, J. F.: Development of a land-cover characteristics database for the conterminous US, Photogramm. Eng. Remote Sens., 57, 1453-1463, 1991.

McDonnell, J. J., Sivapalan, M., Vaché, K., Dunn, S., Grant, G., Haggerty, R., Hinz, C., Hooper, R., Kirchner, J., Roderick, M. L., Selker, J., and Weiler, M.: Moving beyond heterogeneity and process complexity: A new vision for watershed hydrology, Water Resour. Res., 43, W07301, doi:10.1029/2006wr005467, 2007.

Merwade, V., Olivera, F., Arabi, M., and Edleman, S.: Uncertainty in Flood Inundation Mapping: Current Issues and Future Directions, J. Hydrol. Eng., 13, 608-620, doi:10.1061/(ASCE)10840699(2008)13:7(608), 2008.

Merz, R. and Blöschl, G.: Regionalisation of catchment model parameters, J. Hydrol., 287, 95-123, doi:10.1016/j.jhydrol.2003.09.028, 2004.
Nash, J. E. and Sutcliffe, J. V.: River flow forecasting through conceptual models part I - A discussion of principles, J. Hydrol., 10, 282-290, doi:10.1016/0022-1694(70)90255-6, 1970.

Oudin, L., Andréassian, V., Perrin, C., Michel, C., and Le Moine, N.: Spatial proximity, physical similarity, regression and ungaged catchments: A comparison of regionalization approaches based on 913 French catchments, Water Resour. Res., 44, W03413, doi:10.1029/2007wr006240, 2008.

Oudin, L., Kay, A., Andréassian, V., and Perrin, C.: Are seemingly physically similar catchments truly hydrologically similar?, Water Resour. Res., 46, W11558, doi:10.1029/2009wr008887, 2010.

Parajka, J., Merz, R., and Blöschl, G.: A comparison of regionalisation methods for catchment model parameters, Hydrol. Earth Syst. Sci., 9, 157-171, doi:10.5194/hess-9-157-2005, 2005.

Patil, S. and Stieglitz, M.: Hydrologic similarity among catchments under variable flow conditions, Hydrol. Earth Syst. Sci., 15, 989997, doi:10.5194/hess-15-989-2011, 2011.

Sankarasubramanian, A., Vogel, R. M., and Limbrunner, J. F.: Climate elasticity of streamflow in the United States, Water Resour. Res., 37, 1771-1781, doi:10.1029/2000wr900330, 2001.

Sawicz, K., Wagener, T., Sivapalan, M., Troch, P. A., and Carrillo, G.: Catchment classification: empirical analysis of hydrologic similarity based on catchment function in the eastern USA, Hydrol. Earth Syst. Sci., 15, 2895-2911, doi:10.5194/hess-15-28952011, 2011.

Searcy, J. K.: Flow-duration curves: Water Supply Paper 1542-A, U.S. Geological Survey, Reston, VA, 1959.

Seibert, J.: Regionalisation of parameters for a conceptual rainfall-runoff model, Agr. Forest Meteorol., 98-99, 279-293, doi:10.1016/s0168-1923(99)00105-7, 1999.

Sivapalan, M., Takeuchi, K., Franks, S. W., Gupta, V. K., Karambiri, H., Lakshmi, V., Liang, X., McDonnell, J. J., Mendiondo, E. M., O’Connell, P. E., Oki, T., Pomeroy, J. W., Schertzer, D., Uhlenbrook, S., and Zehe, E.: IAHS Decade on Predictions in Ungauged Basins (PUB), 2003-2012: Shaping an exciting future for the hydrological sciences, Hydrolog. Sci. J., 48, 857-880, doi:10.1623/hysj.48.6.857.51421, 2003.

Skøien, J. O. and Blöschl, G.: Spatiotemporal topological kriging of runoff time series, Water Resour. Res., 43, W09419, doi:10.1029/2006wr005760, 2007.

Skøien, J. O., Merz, R., and Blöschl, G.: Top-kriging - geostatistics on stream networks, Hydrol. Earth Syst. Sci., 10, 277-287, doi:10.5194/hess-10-277-2006, 2006.

Slack, J. R., Lumb, A., and Landwehr, J. M.: Hydro-Climatic Data Network (HCDN) Streamflow Data Set, 1874-1988: USGS Water-Resources Investigations Report 93-4076, U.S. Geological Survey, Reston, VA, 1993.

Smakhtin, V. U.: Low flow hydrology: a review, J. Hydrol., 240, 147-186, doi:10.1016/s0022-1694(00)00340-1, 2001.

Smakhtin, V. Y., Hughes, D. A., and Creuse-Naudin, E.: Regionalization of daily flow characteristics in part of the Eastern Cape, South Africa, Hydrolog. Sci. J., 42, 919-936, doi:10.1080/02626669709492088, 1997.

Spearman, C.: The proof and measurement of association between two things, Am. J. Psychol., 15, 72-101, 1904. 
Tate, E., Maidment, D., Olivera, F., and Anderson, D.: Creating a Terrain Model for Floodplain Mapping, J. Hydrol. Eng., 7, 100108, doi:10.1061/(ASCE)1084-0699(2002)7:2(100), 2002.

Vogel, R., Wilson, I., and Daly, C.: Regional Regression Models of Annual Streamflow for the United States, J. Irrig. Drain. Eng.-ASCE, 125, 148, doi:10.1061/(ASCE)07339437(1999)125:3(148), 1999.

Vogel, R. M. and Sankarasubramanian, A.: Monthly Climate Data for Selected USGS HCDN Sites, 1951-1990, Oak Ridge National Laboratory Distributed Active Archive Center, Oak Ridge, Tennessee, USA, 2005.

Wagener, T., Sivapalan, M., McDonnell, J., Hooper, R., Lakshmi, V., Liang, X., and Kumar, P.: Predictions in ungauged basins as a catalyst for multidisciplinary hydrology, Eos Trans. AGU, 85, doi:10.1029/2004eo440003, 2004.

Wagener, T., Sivapalan, M., Troch, P., and Woods, R.: Catchment Classification and Hydrologic Similarity, Geogr. Compass, 1, 901-931, doi:10.1111/j.1749-8198.2007.00039.x, 2007.
Wiche, G. J., Benson, R. D., and Emerson, D. G.: Streamflow at selected gaging stations on the James River in North Dakota and South Dakota, 1953-1982, with a section on climatology, WaterResources Investigations Report 89-4039, US Geological Survey, 99 pp., 1989.

Yadav, M., Wagener, T., and Gupta, H.: Regionalization of constraints on expected watershed response behavior for improved predictions in ungauged basins, Adv. Water Resour., 30, 17561774, doi:10.1016/j.advwatres.2007.01.005, 2007.

Young, A. R.: Stream flow simulation within UK ungauged catchments using a daily rainfall-runoff model, J. Hydrol., 320, 155172, doi:10.1016/j.jhydrol.2005.07.017, 2006.

Zhang, Y. and Chiew, F. H. S.: Relative merits of different methods for runoff predictions in ungauged catchments, Water Resour. Res., 45, W07412, doi:10.1029/2008wr007504, 2009. 